\title{
Processing and characterization of plasticized PLA/PHB blends for biodegradable multiphase systems
}

\author{
I. Armentano ${ }^{1 *}$, E. Fortunati ${ }^{1}$, N. Burgos ${ }^{2}$, F. Dominici ${ }^{1}$, F. Luzi ${ }^{1}$, S. Fiori ${ }^{3}$, A. Jiménez ${ }^{2}$, \\ K. Yoon ${ }^{4}, J$. Ahn ${ }^{4}$, S. Kang ${ }^{4}$, J. M. Kenny ${ }^{1,5}$ \\ ${ }^{1}$ Materials Engineering Center, UdR INSTM, University of Perugia, Strada Pentima Bassa 4, 05100 Terni, Italy \\ ${ }^{2}$ University of Alicante, Dpt. Analytical Chemistry, Nutrition \& Food Sciences, 03690 San Vicente del Raspeig, Spain \\ ${ }^{3}$ Condensia Química S.A. C/ Junqueras 16-11A, 08003 Barcelona, Spain \\ ${ }^{4}$ Bio-materials R\&D team, Samsung Fine Chemicals 130, Samsung-ro, Yeongtong-gu, Suwon-si, Gyeonggi-do 443-803, \\ Korea \\ ${ }^{5}$ Institute of Polymer Science and Technology, CSIC, Madrid, Spain
}

Received 29 October 2014; accepted in revised form 14 January 2015

\begin{abstract}
Blends of poly(lactic acid) (PLA) and poly(3-hydroxybutyrate) (PHB) plasticized with a lactic acid oligomer (OLA) added at three different concentrations (15, 20 and $30 \mathrm{wt} \%$ by weight), were prepared by an optimized extrusion process to improve the processability and mechanical properties of these biopolymers for flexible film manufacturing. Morphological, chemical, thermal, mechanical, barrier and migration properties were investigated and formulations with desired performance in eco-friendly films were selected. The efficiency of OLA as plasticizer for PLA_PHB blends was demonstrated by the significant decrease of their glass transition temperatures and a considerable improvement of their ductile properties. The measured improvements in the barrier properties are related to the higher crystallinity of the plasticized PLA_PHB blends, while the overall migration test underlined that all the proposed formulations maintained migration levels below admitted levels. The PLA_PHB blend with $30 \mathrm{wt} \%$ OLA was selected as the optimum formulation for food packaging, since it offered the best compromise between ductility and oxygen and water vapor barrier properties with practically no migration.
\end{abstract}

Keywords: polymer blends and alloys, poly(lactic acid), poly(hydroxybutyrate), biodegradable, lactic acid oligomers

\section{Introduction}

Reduction of packaging wastes has been a strong motivation for replacing the most common plastics by bio-based and/or biodegradable materials. Simultaneously, the food packaging industry requires the development of simple formulations produced by easy, readily available and cost effective processing technologies such as melt blending approaches [1]. At the same time, consumers demand high quality food with long shelf-life and also they desire see through the packaging to perceive the foodstuff aspect. Thus, food packagings are required to contain food products and protect them from the surroundings avoiding contamination, humidity and oxidations process as well as being transparent enough to allow seeing the food through the packaging. In this context, the efficiency in the use of polymer films in food packaging has however been limited by their poor mechanical properties and by their moisture sensitivity. Improving their processability and tensile properties is an important challenge to be afforded before sending these formulations to the market. Consequently, the modification of these materials is in the focus of scientific research.

\footnotetext{
*Corresponding author, e-mail: ilaria.armentano@unipg.it

(c) BME-PT
} 
In contrast to the development of novel polymeric materials and new polymerization routes, blending is a relatively cheap and fast method to tailor the plastics properties. As a result, this approach may play a crucial role in increasing the competitiveness of biopolymers [2-5]. Poly(lactic acid) (PLA) thereby represents the most investigated aliphatic polyester for a wide range of applications, due to its biodegradability, renewability and excellent mechanical properties, good processability and low cost $[6$, 7]. It is now produced on a large scale and used for various applications in different domains: packaging, medicine, agriculture and textiles. However, high brittleness, slow crystallization rate and low barrier properties of PLA compared to those of synthetic polymers strongly limit its applications in, for instance, food packaging [6]. Several strategies have been attempted for PLA to enhance its crystallization rate as well as to improve its barrier properties. Blending of PLA with other biopolymers or conventional synthetic polymers is one of the most effective methods to obtain new properties required for specific end-use applications [8,9]. For example, blending PLA with poly(hydroxybutyrate) (PHB), a highly crystalline biopolymer with high melting point and among the most studied polyhydroxyalkanoates (PHAs), leads to materials with interesting physical, thermal, and mechanical properties compared to neat PLA [10-12].

PLA and PHB are biodegradable polyesters and they are used in consumer products by several industrial sectors due to their biocompatibility, biodegradability and sustainability $[6,12,13]$. They have comparable thermal and mechanical properties to those of some conventional/non-degradable polymers and this has generated much interest in exploring their physical and processing properties for sustainable packaging applications.

Zhang et al. [11] and Zhang and Thomas [12] reported that PLA melt blended with $25 \mathrm{wt} \%$ of PHB showed optimal miscibility between both polymers and improvement in tensile properties compared to pure PLA, due to the reinforcement effect of the small, finely dispersed and highly crystalline PHB particles with the result of enhancing the PLA crystallinity by the nucleating agent of PHB in PLA matrices. Other authors also found that the addition of PHB significantly improved the crystallinity and crystallization rate of PLA [14]. Furthermore PLA_PHB (75:25) blends showed improved oxy- gen barrier and surface wettability properties, whereas their disintegrability under composting conditions suggested a valuable end-life option for PLA_PHB packaging materials [1].

Similarly, Noda et al. [10] found an improvement in toughness of PLA_PHAs blends, as long as the content of PHAs is not high (below $20 \mathrm{wt} \%$ ). This singular behavior was explained by the unusually slow crystallization kinetics of PHAs, when PHA particles are dispersed in small domains (around $1 \mu \mathrm{m}$ ), leading to rubbery amorphous PHA particles dispersed in the hard and brittle PLA matrix.

On the other hand, with regard to the field of application, plasticizers are frequently incorporated into PLA-based materials, to improve their processability and/or other properties required by a specific application [14]. The addition of plasticizers to PLA allows the production of flexible films by improving its inherent brittle nature. Plasticizers exchange the intermolecular bonds among polymer chains to bonds between the macromolecules and the small molecular weight compound, thus promoting conformational changes resulting in increased deformability. Both, the glass transition and the processing temperatures of the material decrease, thus enabling the melt processing of heat-sensitive polymers at lower temperatures $[4,5,11,12,15,16]$. Concerning food contact materials, plasticizers should meet several requirements, in particular being non-toxic, showing good compatibility with the polymer and providing suitable thermal, mechanical and barrier properties. Besides transparency, their low volatility and low migration to foodstuff are also relevant parameters to ensure the permanence of the plasticizer in the polymer matrix, and consequently the stability of films during their shelf life. Several compounds have been studied as potential PLA plasticizers, such as triacetine, citrate esters [17], glycerol [18], malonate oligomers, adipates and polyadipates, poly(ethylene glycol) (PEG) [19], poly(propylene glycol) (PPG) or their copolymers. However, their incorporation into PLA without showing phase separation over time was restricted to concentrations lower than $20 \mathrm{wt} \%$ in all cases [20]. In general, it has been accepted that amounts from 10 to $20 \mathrm{wt} \%$ of plasticizers are required to provide a substantial reduction in the PLA glass transition temperature $\left(T_{\mathrm{g}}\right)$ as well as to obtain adequate mechanical properties for films manufacturing. The ideal approach to increase miscibility between PLA and potential 
plasticizers would be to add a compound with similar chemical structure and a relatively high molar mass to reduce migration rate and detrimental changes in the material properties over time [21]. Martin and Averous reported the addition of glycerol and oligomeric lactic acid (OLA) to PLA and compared both with other plasticizers, such as citrate ester and polyethylene glycol (PEG) with different average molecular weight. Conclusions were drawn that glycerol was the least efficient plasticizer, and OLA and the lower molecular weight PEG gave the best performance to increase ductile properties in PLA $[19,22]$.

The aim of this paper is to study the effects of OLA on PLA_PHB blends to improve the polymer and blend processability for films manufacturing with selection of adequate OLA contents to get the desired performance and to create a new type of eco-friendly blends suitable for single-use applications, such as fast-food packaging.

\section{Experimental part}

\subsection{Materials}

Commercial poly(lactic acid) PLA 3051D, was purchased from NatureWorks ${ }^{\circledR}$ Co. LLC, USA. This PLA grade shows specific gravity $1.25 \mathrm{~g} \cdot \mathrm{cm}^{-3}$, molecular weight $\left(M_{\mathrm{n}}\right) 1.42 \cdot 10^{4} \mathrm{~g} \cdot \mathrm{mol}^{-1}$, and a melt flow index (MFI) of $7.75 \mathrm{~g} / 10 \mathrm{~min}$ tested at $210^{\circ} \mathrm{C}$ and $2.16 \mathrm{~kg}$ loading.

Poly(3-hydroxybutyrate) (PHB), was supplied by NaturePlast (France). This PHB grade has a density of $1.25 \mathrm{~g} \cdot \mathrm{cm}^{-3}$, MFI $15-30 \mathrm{~g} / 10 \mathrm{~min}$ tested at $190^{\circ} \mathrm{C}$ and $2.16 \mathrm{~kg}$ loading.

The plasticizer selected for this study is based on oligomeric lactic acid (OLA), developed and provided by Condensia Quimica S.A (Barcelona, Spain) [23]. OLA was synthesized as described elsewhere [21] and it was produced as a slightly colored liquid with molar mass $\left(M_{\mathrm{n}}\right)$ of $957 \mathrm{~g} \cdot \mathrm{mol}^{-1}$ (determined by size exclusion chromatography) and glass transition temperature around $-37^{\circ} \mathrm{C}$ (determined by differential scanning calorimetry, DSC).

\subsection{Processing of binary and ternary blends}

PLA and PHB were pre-dried to get rid of any moisture trace in the polymer structure and to avoid any undesirable hydrolysis reaction during processing. PLA was put into an oven at $98^{\circ} \mathrm{C}$ for $3 \mathrm{~h}$, while PHB was dried at $70^{\circ} \mathrm{C}$ for $4 \mathrm{~h}$. PLA and PLA/PHB based formulations were processed and mixed by using a twin-screw microextruder (Dsm Explore 5\&15 CC Micro Compounder). Processing parameters (screw speed, mixing time and temperature profile) were modulated to optimize the extrusion procedure. The selected ratio content of PHB was $15 \mathrm{wt} \%$ in the PLA/PHB blends.

OLA was pre-heated at $100^{\circ} \mathrm{C}$ for $5 \mathrm{~min}$, to ensure the liquid condition during the extrusion process.

Three different OLA concentrations were selected based on the results obtained in a previous report [20]: 15, 20 and $30 \mathrm{wt} \%$, as shown in Table 1.

PLA and PLA_PHB blend films with thicknesses between 20 and $60 \mu \mathrm{m}$ were obtained by extrusion with the adequate filmature tip. Screw speed at $100 \mathrm{rpm}$ was used to optimize the material final properties, while the temperature profile was set up at $180-190-200^{\circ} \mathrm{C}$ in the three different extrusion areas. The total processing time was established at 6 minutes. PLA alone was mixed for $6 \mathrm{~min}$; in the case of PLA 15PHB blend, i.e. PLA was processed for the first 3 min and PLA_PHB for the remaining $3 \mathrm{~min}$, while in the PLA_PHB_OLA systems, PLA_PHB was previously mixed for $3 \mathrm{~min}$ and OLA was added to the polymeric blend for the last 3 min (Table 1).

\subsection{Characterization techniques 2.3.1. Morphology}

The transparency of the films was evaluated by visual observation, while the morphology and micro-

Table 1. Material formulations and process parameters

\begin{tabular}{|l|c|c|c|c|c|c|}
\hline \multirow{2}{*}{ Formulations } & \multicolumn{3}{|c|}{ Component contents } & \multicolumn{3}{c|}{ Mixing parameters } \\
\cline { 2 - 6 } & $\begin{array}{c}\text { PLA } \\
{[\mathbf{w t} \%]}\end{array}$ & $\begin{array}{c}\text { PHB } \\
{[\mathbf{w t} \%]}\end{array}$ & $\begin{array}{c}\text { OLA } \\
{[\mathbf{w t} \%]}\end{array}$ & $\begin{array}{c}\text { Speed } \\
{[\mathbf{r p m}]}\end{array}$ & $\begin{array}{c}\text { Mixing time } \\
\text { Temin] }\end{array}$ & $\begin{array}{c}\text { Temperature profile } \\
{\left[{ }^{\circ} \mathbf{C}\right]}\end{array}$ \\
\hline PLA & 100 & 0 & 0 & 100 & $180-190-200$ \\
\hline PLA_15PHB & 85 & 15 & 0 & 100 & $3+3^{*}$ & $180-190-200$ \\
\hline PLA_15PHB_15OLA & 70 & 15 & 15 & 100 & $3+3^{* *}$ & $180-190-200$ \\
\hline PLA_15PHB_20OLA & 65 & 15 & 20 & 100 & $3+3^{* *}$ & $180-190-200$ \\
\hline PLA_15PHB_30OLA & 55 & 15 & 30 & 100 & $3+3^{* *}$ & $180-190-200$ \\
\hline
\end{tabular}

*3 min mixing PLA and 3 min mixing PLA_PHB

** 3 min mixing PLA_PHB and 3 min mixing PLA_PHB_OLA 
structure of the fracture surfaces of PLA, PLA_PHB and PLA_PHB_OLA films were investigated by field emission scanning electron microscope (FESEM Supra 25, Zeiss, Germany). Films were previously freeze-cut in liquid nitrogen, gold coated with an Agar automatic sputter coated and then analysed.

\subsubsection{X-ray diffraction (XRD)}

Crystalline/amorphous character of all blends was evaluated by Wide angle X-ray scattering (WAXS) by using a Bruker D8-Advance (Madison, WI, USA) diffractometer, equipped with a $\mathrm{Cu} \mathrm{K} \alpha$ radiation source $(\lambda=1.546 \AA)$, operating at $40 \mathrm{kV}$ and $40 \mathrm{~mA}$ as the applied voltage and current, respectively. The incidence angle (2 $\theta$ ) was varied between 2 and $90^{\circ}$ at a scanning rate of $2^{\circ} \cdot \mathrm{min}^{-1}$.

\subsubsection{Thermal analysis}

Differential scanning calorimetry (DSC) tests were carried out with a TA Instruments Mod. Q200 calorimeter to determine the effect of the OLA content on the glass transition temperature $\left(T_{\mathrm{g}}\right)$ of PLA and PLA_PHB blends. Tests were performed in three cycles (two heating and one cooling scans) from -25 to $200^{\circ} \mathrm{C}$, at $10^{\circ} \mathrm{C} \cdot \mathrm{min}^{-1}$. Glass transition, crystallization and melting phenomena in PLA, PLA_PHB and PLA_PHB_OLA blends were determined.

Degree of crystallinity $X_{\mathrm{c}}$ was calculated by using Equation (1):

$X_{\mathrm{c}}=\frac{\Delta H_{\mathrm{m}}-\Delta H_{\mathrm{cc}}}{w \cdot \Delta H_{\mathrm{m}}^{0}}$

where $\Delta H_{\mathrm{m}}$ and $\Delta H_{\mathrm{cc}}$ are the enthalpy of melting and cold crystallization peaks, respectively; $w$ is the weight fraction of PLA polymer in the sample and $\Delta H_{\mathrm{m}}^{0}$ is the heat of melting of purely crystalline PLA, considering these values as $93 \mathrm{~J} \cdot \mathrm{g}^{-1}[4,5]$.

Thermal degradation behavior of PLA-based formulations was evaluated by thermogravimetric analysis (TGA, Seiko Exstar 6300, Tokyo, Japan); 5 mg samples were used and dynamic tests were performed in nitrogen atmosphere $\left(250 \mathrm{~mL} \cdot \mathrm{min}^{-1}\right)$ from 30 to $600^{\circ} \mathrm{C}$ at $10^{\circ} \mathrm{C} \cdot \mathrm{min}^{-1}$. Thermal degradation temperatures $\left(T_{\max }\right)$ for each tested material were evaluated.

\subsubsection{Infrared spectroscopy (FT-IR)}

FT-IR spectra were obtained at room temperature in reflection mode by attenuated total reflectance (ATR) with a FT-IR spectrometer (Jasco FT-IR 615, Japan). The scanned wave number range was 4000 $600 \mathrm{~cm}^{-1}$, at $4 \mathrm{~cm}^{-1}$ of spectral resolution.

\subsubsection{Tensile tests}

The tensile properties of neat PLA, PLA_PHB, and PLA_PHB_OLA blends were evaluated. Tests were performed on $50 \times 10 \mathrm{~mm}^{2}$ rectangular probes as indicated in the UNI EN ISO 527-5 standard, with a crosshead speed $1 \mathrm{~mm} \cdot \mathrm{min}^{-1}$ and a load cell $50 \mathrm{~N}$. These tests were carried out in a digital Lloyd testing machine (Lloyd Instrument LR 30K Segensworth West, Foreham, UK) and the initial grip separation was $25 \mathrm{~mm}$. Tensile strength $\left(\sigma_{\mathrm{b}}\right)$, failure strain $\left(\varepsilon_{\mathrm{b}}\right)$, yield strength $\left(\sigma_{\mathrm{y}}\right)$, yield strain $\left(\varepsilon_{\mathrm{y}}\right)$ and elastic modulus $(E)$ were calculated from the resulting stressstrain curves. These measurements were performed at room temperature and at least six samples were tested for each specimen.

\subsubsection{Barrier properties}

Films of PLA and PLA_PHB blends for barrier properties testing were obtained by compression moulding. Blends were melted at $170^{\circ} \mathrm{C}$ in a Carver Inc. Hot Press (Wabash, Indiana, USA) by keeping them between the press plates for 4 minutes at atmospheric pressure. Then, pressure was gradually increased during 2 minutes up to $5 \mathrm{MPa}$ and maintained for 5 minutes. Circular films with homogeneous thickness $(235 \pm 15) \mu \mathrm{m}$ and $14 \mathrm{~cm}$ diameter were obtained. The Oxygen Transmission Rate (OTR) tests were conducted with an Oxygen Permeation Analyser 8500 from Systech Instruments (Metrotec S.A, Spain) at $23^{\circ} \mathrm{C}$.

Pure oxygen (99.9\%) was introduced into the upper half of the chamber while nitrogen was injected into the lower half, where an oxygen sensor was placed. The oxygen volumetric flow rate per unit area of the membrane (OTR, $\mathrm{cm}^{3} \mathrm{~m}^{-2}$ day $\left.^{-1}\right)$ was continuously monitored until a steady state was reached. The permeability coefficient is dependent on the film thickness and proportional to OTR $e$ ( $e=$ thickness, $\mathrm{mm}$ ). Therefore, the OTR $\cdot e$ values were used to compare the oxygen barrier properties of the films. All samples were analyzed in triplicate.

Water Vapor Permeability coefficient $(W V P)$ was determined gravimetrically using the ASTM E96/E96 M-05 [24] standard and it was calculated in $\mathrm{kg} \cdot \mathrm{m} \cdot \mathrm{Pa}^{-1} \cdot \mathrm{s}^{-1} \cdot \mathrm{m}^{-2}$ by using Equation (2): 
$W V P=\frac{W V T \cdot e}{\Delta P}$

where $W V T\left(\mathrm{~kg} \cdot \mathrm{s}^{-1} \cdot \mathrm{m}^{-2}\right)$ is the water vapor transmission rate through an average film thickness $e$ (m) and $\Delta P$ is the vapor pressure difference between the two sides of the specimens $(\mathrm{Pa})$, calculated by using Equation (3):

$\Delta P=S\left(R_{1}-R_{2}\right)$

where $S$ is the saturation vapor pressure at the testing temperature $(\mathrm{Pa})$ and $R_{1}, R_{2}$ are the relative humidity of the climate chamber and inside the dish, respectively. $W V P$ tests were performed using the desiccant method, where samples $(90 \mathrm{~mm}$ diameter circles) were sealed with paraffin to the test stainless steel dishes containing anhydrous calcium chloride (pre-dried at $200^{\circ} \mathrm{C}$ for $2 \mathrm{~h}$ ) as desiccant agent. These dishes were placed in a climate chamber at $23 \pm 1{ }^{\circ} \mathrm{C}$ and $R H 50 \pm 2 \%$, and were weighed periodically until the steady state was reached. The weight change in the dishes compared with the initial mass $G,( \pm 0.001 \mathrm{~g})$, was plotted versus time at $24 \mathrm{~h}$ intervals, $t(\mathrm{~h})$. Linear regression was used to calculate the slope of a fitted straight line $(G / t)$ allowing the $W V T$ calculation by using Equation (4):

$W V T=\frac{G / t}{A}$

Where $A$ is the effective area of the test film $\left(0.01 \mathrm{~m}^{2}\right)$. All values reported in this study are the average of three replicate samples $(n=3) \pm$ standard deviation $(S D)$.

\subsubsection{Migration tests}

Overall migration tests for all materials were performed in two liquid food simulants: ethanol $10 \%$ (v/v) (simulant $A$ ) in agreement with the Commission Regulation EU N ${ }^{\circ} 10 / 2011$ [25] and isooctane (alternative simulant to D2) according to the Commission Directive 2002/72/EC [26]. Rectangular sheets of $2.5 \times 10 \mathrm{~cm}^{2}$ were totally immersed in $25 \mathrm{~mL}$ of food simulant in both cases in triplicate. Whereas the most common use of a material for contact with food is at room temperature for more than one day, the test conditions selected were more restrictive, as indicated in the current legislation. Samples in ethanol 10\% (v/v) were kept in an oven at $40^{\circ} \mathrm{C}$ for 10 days, while samples in isooctane were kept in a climate chamber at $20^{\circ} \mathrm{C}$ for 2 days. After the contact time, films were removed and the simulants were totally evaporated and dried in an oven at $105^{\circ} \mathrm{C}$ for 30 minutes. Mass of the non-volatile residue was determined with an analytical balance ( $\pm 0.1 \mathrm{mg}$ accuracy) until constant weight $( \pm 0.5 \mathrm{mg})$ to determine the overall migration value in $\mathrm{mg} \cdot \mathrm{kg}^{-1}$ of simulant. All overall migration values of samples are the average of three determinations $(n=3) \pm$ standard deviation $(S D)$.

\subsubsection{Statistical analysis}

Analysis of variance (ANOVA) for barrier properties and migration tests and significance in the data differences were carried out by using SPSS statistics 22.0 software. Tukey's multiple sample comparison method with a 95\% confidence level ( $p<$ 0.05 ) was used to identify which data groups were significantly different from others.

\section{Results and discussion}

In order to analyze the stability of the OLA during the processing conditions, a thermogravimetric test in isothermal conditions (air atmosphere at $200^{\circ} \mathrm{C}$, for $30 \mathrm{~min}$ ) was performed to simulate the processing thermal profile (Figure 1). Some weight losses for pure OLA were observed at $200^{\circ} \mathrm{C}$, but they were moderate in comparison with other plasticizers for PLA used in previous works in the research group $[27,28]$. No significant phase separation should be expected at the selected concentrations, giving evidence of the thermal resistance of this plasticizer under the processing conditions selected for these blends.

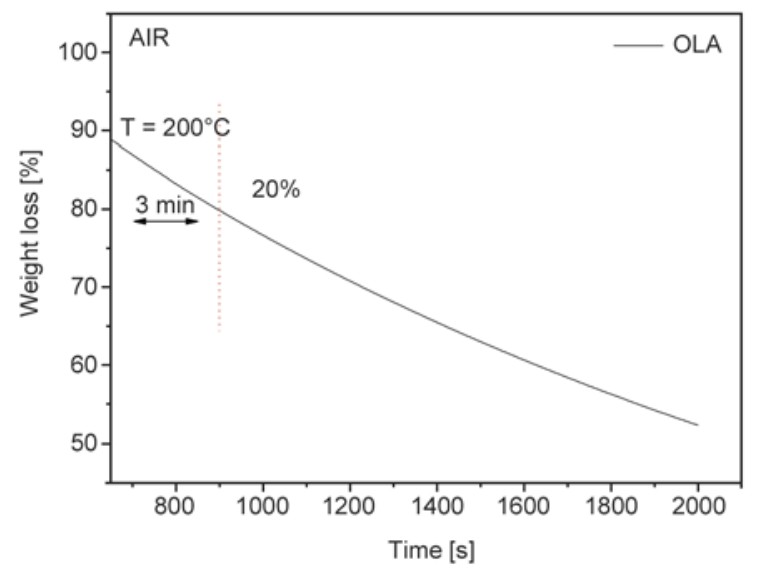

Figure 1. OLA isothermal test in air at $200^{\circ} \mathrm{C}$, for $30 \mathrm{~min}$ 
Hence PLA, PLA_PHB and PLA_PHB_OLA films were successfully developed by extrusion process, with the selected process parameters.

\subsection{Transparency and microstructure}

The visual appearance and transparency of PLA and PLA_PHB based blends after the optimized extrusion process were investigated and summarized in Figure 2. Images underline that all the produced samples appeared colourless and maintained the good and typical transparency of the PLA matrix, also in the case of the higher content of OLA.

Figure 3 gives the FESEM images of the fracture surface of the films, for the neat PLA, PLA_PHB blend and the plasticized (PLA_PHB_OLA) samples with various OLA concentrations, at different resolutions. Neat PLA showed a smooth and uniform surface typical of a semicrystalline polymer. FESEM images of PLA_PHB films underlined that the dispersed PHB phase had relatively small average diameter and, with a typical sea-island morphology, where the discrete PHB spherical domains are dispersed in the PLA polymer matrix. With the addition of OLA, the size of the PHB domains reduced remarkably.

Moreover, the blend system showed better interfacial adhesion between both phases in the presence of the plasticizer. This indicates that the addition of OLA improved the interfacial properties of the immiscible PLA_PHB blend, with similar results to those obtained by adding a compatibilizer.

On the other hand, the surface of the specimens with OLA showed a different aspect. Shear-yield and plastic deformation formed on the fracture surfaces of OLA based blends were observed, especially for the system with the highest plasticizer content (Figure 3). Plastic deformation and the different fracture directions required more energy and thus the materials with OLA should have higher toughness.

\subsection{X-ray diffraction (XRD)}

Figure 4 shows the diffraction patterns of neat PLA, and ternary PLA_PHB_OLA films. In the case of the neat PLA film, a diffraction peak at $2 \theta=16.5^{\circ}$ was observed, which corresponds to the characteristic peak of PLA $[12,20]$ and indicates the development of a certain crystallinity degree after processing. The diffraction patterns of PLA_PHB, showed amorphous structure at room temperature with no diffraction peaks other than the amorphous

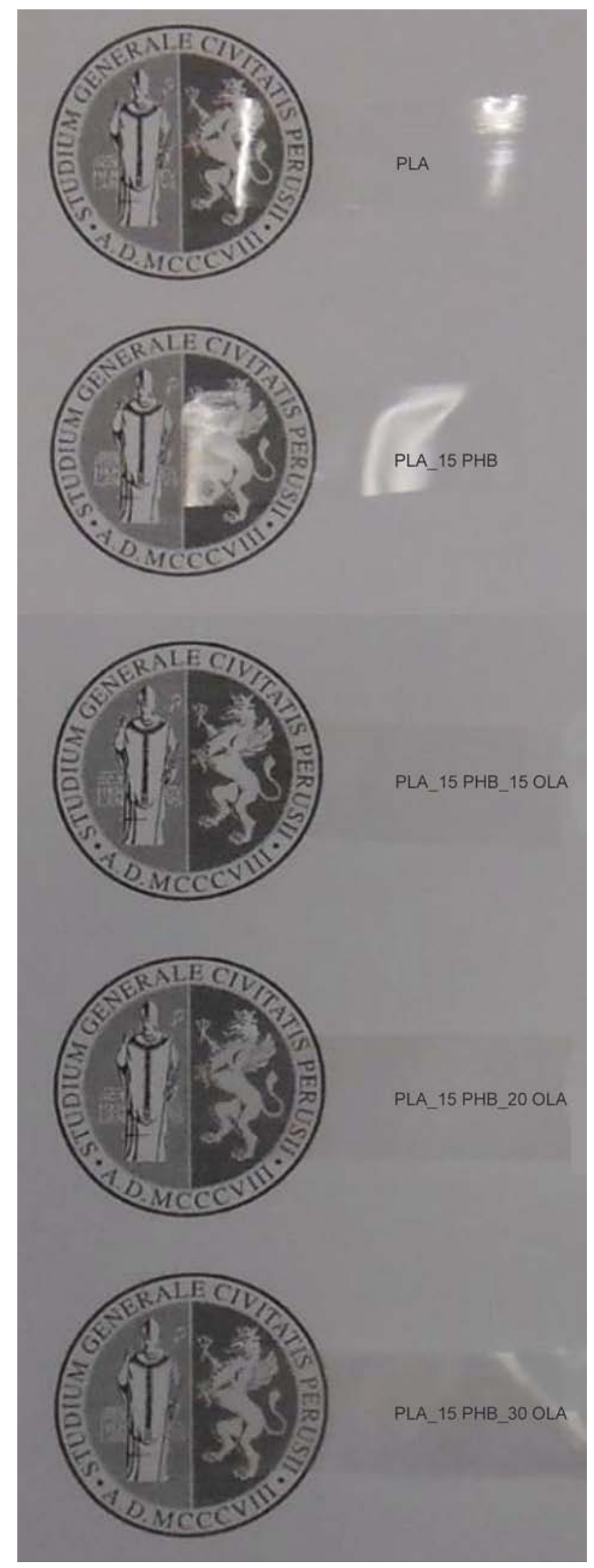

Figure 2. Images of neat PLA, PLA_PHB, and PLA_PHB_OLA films

halo. This result could be explained by the low PHB content in the PLA matrix and the interaction between both biopolymers, reducing their crystal- 

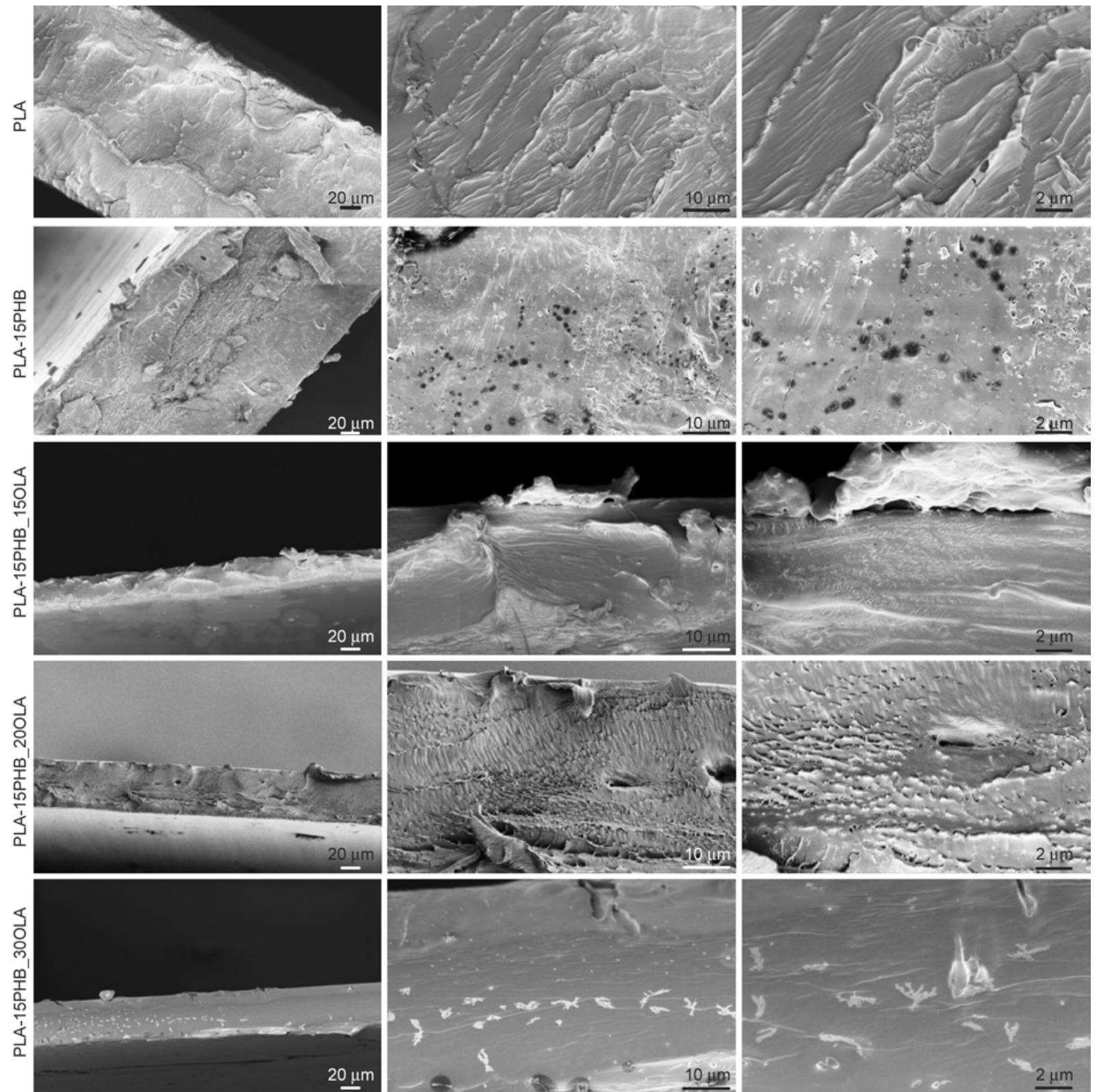

Figure 3. FESEM images of PLA, PLA_PHB and PLA_PHB_OLA films at different resolution and OLA concentration

lization rate, as other authors observed for this blends [12]. However, the addition of OLA induced

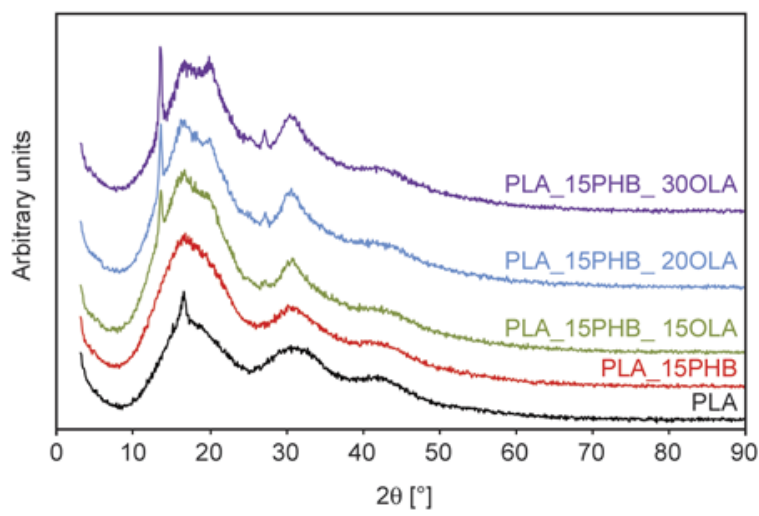

Figure 4. X-Ray diffraction patterns of PLA, PLA_PHB and PLA_PHB_OLA films the development of crystallinity, which was higher with the plasticizer content (Figure 4). In the PLA_15PHB_15OLA film two diffraction peaks at $2 \theta=13.5$ and $27.2^{\circ}$ (with lower definition) were observed. The first one corresponds to the characteristic peak of PHB crystallinity, while the other characteristic peak of this polymer $\left(2 \theta=17^{\circ}\right)$ was overlapped by the peak at $2 \theta=16.5^{\circ}$ attributed to PLA $[4,16]$. The intensity of these peaks increased for 20 and $30 \mathrm{wt} \%$ OLA content and the band at $30.1^{\circ}$ became more defined. Furthermore, one additional peak at $19.8^{\circ}$ was observed for higher OLA concentrations. These results imply that the presence of OLA improved the interaction between PLA and PHB and consequently the development of crystallinity in the blends structure, with a clear 
incidence on the mechanical properties of these blends.

\subsection{Thermal analysis}

Differential scanning calorimetry (DSC) analysis of different formulations was conducted in order to determine the effect of the OLA introduction and content on the glass transition temperature $\left(T_{\mathrm{g}}\right)$, and on crystallization and melting phenomena of PLA_PHB based systems. DSC thermograms at the first heating, cooling and second heating scan are reported in Figure 5a, 5b and 5c respectively, while the thermal properties of the PLA, PLA_PHB and PLA_PHB_OLA ternary systems after processing are summarized in Table 2.

The thermogram of neat PLA during the first heating scan displayed the glass transition temperature, the cold crystallization exotherm with its maximum at $T_{\mathrm{cc}}$ and the melting endotherm at $T_{\mathrm{m}}$ (Figure 5a). The $T_{\mathrm{g}}$ value for PLA neat film was about $60^{\circ} \mathrm{C}$, while the exothermic peak was observed at about $95^{\circ} \mathrm{C}$ and the melting endothermic peak was obtained at about $150^{\circ} \mathrm{C}$. In depth analysis, these thermograms revealed a sharp endothermic peak associated to the glass transition, typically attributed to the enthalpy relaxation on heating mostly due to the previous physical aging of the polymer. Moreover, during the cooling scan (Figure 5b) no exothermic crystallization peaks were obtained for PLA and this behaviour was also detected for all the PLAbased systems; the slight change in the baseline observed between 30 and $53^{\circ} \mathrm{C}$ was attributed to the glass transition (Figure 5b). DSC thermograms for the PLA_PHB blend underlined a slightly shift to lower $T_{\mathrm{g}}$ values with respect to neat PLA while the PLA_PHB blend showed a multi-step melting process with the first and second peaks ( $T_{\mathrm{m}}^{\prime}$ and $\left.T_{\mathrm{m}}^{\prime \prime}\right)$ due to the PLA component and the third one $\left(T_{\mathrm{m}}^{\prime \prime \prime}\right)$ corresponding to the melting of PHB component measured at $173^{\circ} \mathrm{C}$, in the pristine pellets, suggesting no complete miscibility between both polymers [4]. Moreover, the double melting peak at around 145$150^{\circ} \mathrm{C}$ and related to the PLA component could be attributed to the formation of different crystal structures. The same behavior was detected also for the second heating scan (Figure 5c).

As expected, the addition of OLA produced a significant reduction on the $T_{\mathrm{g}}$ values of PLA_PHB blends, clearly evident in both first heating and cooling scan. This effect could be explained by the plas-
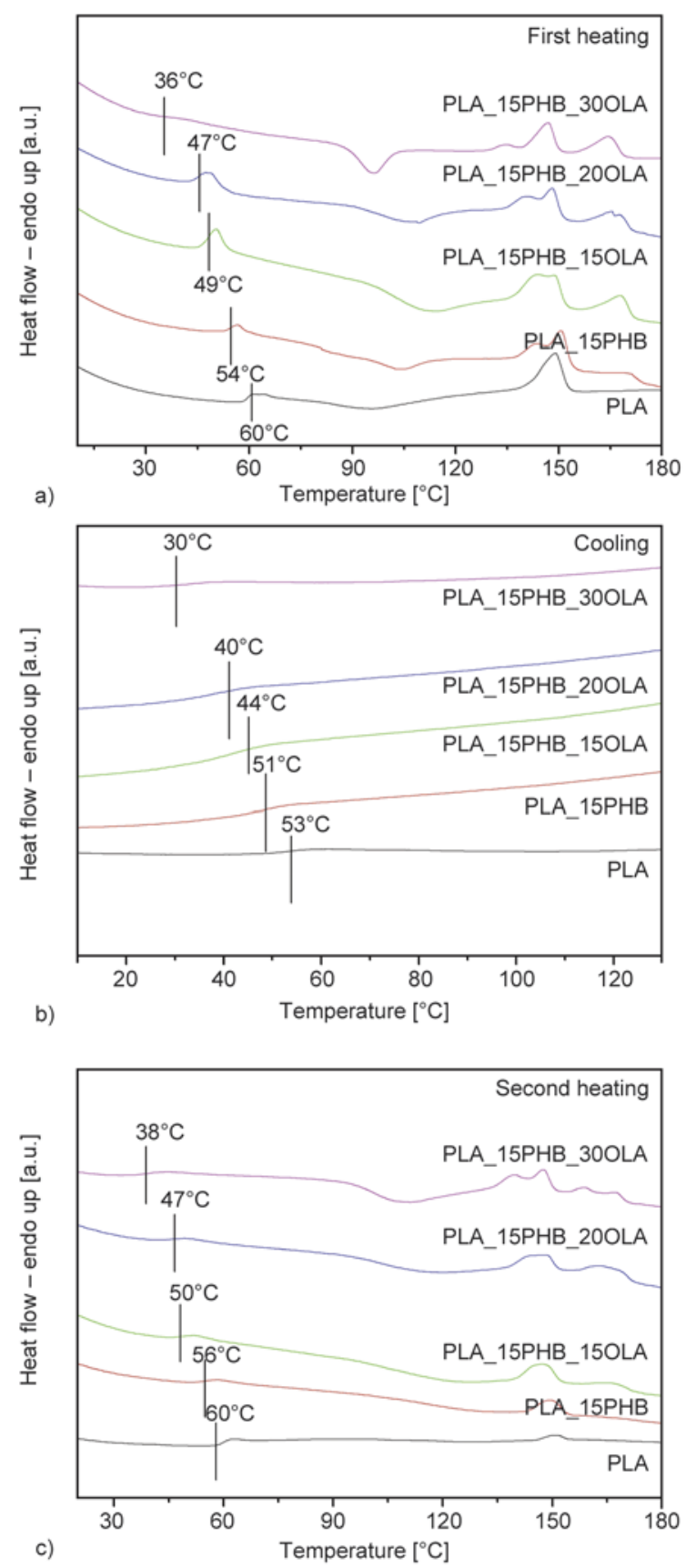

Figure 5. DSC thermograms for PLA, PLA_PHB and PLA_PHB_OLA based systems at the first heating after processing (a), during the cooling scan (b) and at the second heating scan (c).

ticizing effect of OLA resulting in the increase of the molecular mobility of the polymer structure and lower glass transition temperatures. Furthermore, the OLA presence increased the ability of PLA to crystallize confirming the XRD results. This effect was evidenced by the increase of the exothermic peak corresponding to cold crystallization, with a shift to higher $T_{\mathrm{cc}}$ values on the ternary PLA_PHB_OLA systems, and by the crystallinity degree values reported 
Table 2. Thermal properties of PLA, PLA_PHB binary and PLA_PHB_OLA ternary systems at the first heating scan, after processing

\begin{tabular}{|l|c|c|c|c|c|c|c|c|}
\hline \multicolumn{1}{|c|}{ Materials } & $\begin{array}{c}\mathbf{T}_{\mathbf{g}} \\
{\left[{ }^{\circ} \mathbf{C}\right]}\end{array}$ & $\begin{array}{c}\mathbf{T}_{\mathbf{c c}} \\
{\left[{ }^{\circ} \mathbf{C}\right]}\end{array}$ & $\begin{array}{c}\Delta \mathbf{H}_{\mathbf{c c}} \\
{\left[\mathbf{J}^{-1} \mathbf{g}^{-1}\right]}\end{array}$ & $\begin{array}{c}\mathbf{T}_{\mathbf{m}}^{\prime} \\
{\left[{ }^{\circ} \mathbf{C}\right]}\end{array}$ & $\begin{array}{c}\mathbf{T}_{\mathbf{m}}^{\prime \prime} \\
{\left[{ }^{\circ} \mathbf{C}\right]}\end{array}$ & $\begin{array}{c}\mathbf{T}_{\mathbf{m}}^{\prime \prime \prime} \\
{\left[{ }^{\circ} \mathbf{C}\right]}\end{array}$ & $\begin{array}{c}\Delta \mathbf{H}_{\mathbf{m}} \\
{\left[\mathbf{J}^{-1} \mathbf{g}^{-1}\right]}\end{array}$ & $\begin{array}{c}\mathbf{X}_{\mathbf{c}} \\
{[\mathbf{\%}]}\end{array}$ \\
\hline PLA & $60.1 \pm 1.0$ & $95.1 \pm 0.8$ & $15.8 \pm 0.7$ & $150.0 \pm 0.5$ & - & - & $27.6 \pm 0.4$ & $12.7 \pm 0.8$ \\
\hline PLA_15PHB & $55.4 \pm 1.2$ & $103.6 \pm 0.5$ & $9.3 \pm 0.6$ & $144.0 \pm 0.9$ & $150.2 \pm 0.5$ & $170.4 \pm 1.0$ & $25.4 \pm 0.5$ & $20.4 \pm 0.7$ \\
\hline PLA_15PHB_15OLA & $49.4 \pm 1.4$ & $111.5 \pm 0.3$ & $19.1 \pm 0.8$ & $143.4 \pm 0.2$ & $148.4 \pm 0.7$ & $167.9 \pm 0.5$ & $27.6 \pm 0.8$ & $13.1 \pm 1.0$ \\
\hline PLA_15PHB_20OLA & $47.2 \pm 1.3$ & $107.7 \pm 0.5$ & $18.2 \pm 0.7$ & $140.7 \pm 0.2$ & $148.1 \pm 0.5$ & $166.8 \pm 0.5$ & $33.2 \pm 0.4$ & $24.8 \pm 0.8$ \\
\hline PLA_15PHB_30OLA & $36.2 \pm 1.4$ & $95.6 \pm 0.5$ & $22.6 \pm 0.7$ & $134.6 \pm 0.5$ & $146.1 \pm 0.6$ & $164.8 \pm 0.5$ & $34.1 \pm 0.2$ & $22.5 \pm 0.8$ \\
\hline
\end{tabular}

in the Tables 2. Furthermore, the increase in chain mobility of PLA with a higher amount of OLA shifted the melting temperatures $\left(T_{\mathrm{m}}\right)$ to lower values (Table 2) and also the $T_{\mathrm{m}}^{\prime \prime \prime}$, related to the PHB melting, was shifted to lower temperatures by the presence of OLA [20]. It is also assumed that OLA does not crystallize after processing and does not interfere in the PLA and PLA_PHB crystallization process, since just low-intensity melting peak at around $78^{\circ} \mathrm{C}$ was observed in the DSC thermogram in the first heating scan. No further crystallization and melting peaks were observed during the second heating scan.

Thermogravimetric analysis was also performed in order to establish the effect of OLA introduction on the PLA_PHB system thermal stability and the weight loss derivative curves (DTG) for neat PLA, PLA_PHB blend and PLA_PHB_OLA based formulations are reported in Figure 6.

Neat PLA film decomposed in a single step process with a maximum degradation peak $\left(T_{\max }\right)$ at $361^{\circ} \mathrm{C}$, in agreement with values previously reported after processing [29] while a two-steps degradation behaviour was observed in the case of the PLA_PHB blend and the ternary PLA_PHB_OLA systems with a first peak at lower temperatures (around $280^{\circ} \mathrm{C}$ )

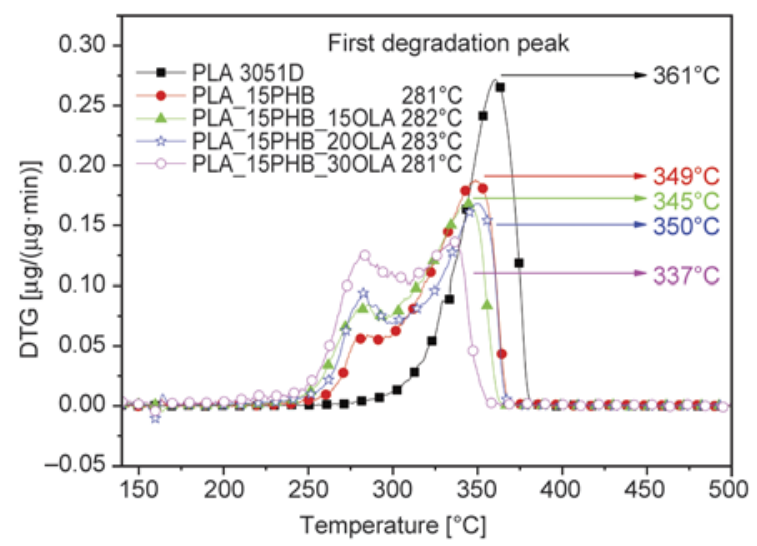

Figure 6. Thermogravimetric analysis of PLA, PLA_PHB and PLA_PHB_OLA based systems under nitrogen atmosphere due to the PHB thermal degradation and a second degradation peak at higher temperatures attributed to the PLA degradation. Moreover, a shift to lower temperatures of the main degradation peak was detected for the PLA_PHB blend $\left(T_{\max }=349^{\circ} \mathrm{C}\right)$ when compared to neat PLA. It should be noted that the introduction of OLA at 15 and $20 \mathrm{wt} \%$ did not result in a significant change in the PLA_PHB thermal stability $\left(T_{\max }=345\right.$ and $350^{\circ} \mathrm{C}$, respectively), ensuring the wide processing window with no risk of thermal degradation. However, a more evident decrease (about $15^{\circ} \mathrm{C}$ in the main degradation peak) was observed for the PLA_15PHB_30OLA ( $T_{\max }=$ $337^{\circ} \mathrm{C}$ ) blend respect to PLA_PHB formulation and an increase of the intensity of the first degradation peak (at lower temperature) was registered for all PLA_PHB_OLA systems with the increased OLA content that can modify the thermal stability of the system.

\subsection{FTIR analysis}

Figure 7 shows the FTIR spectra of the PLA, PLA_PHB and PLA_PHB_OLA films in the 2000$600 \mathrm{~cm}^{-1}$ region (Figure 7a) and in the 1900 $1600 \mathrm{~cm}^{-1}$ region (Figure 7b). FTIR spectra displayed the typical absorption bands of PLA based systems. Several absorption bands specific for PHB and PLA were detected. Since differences in the initial crystallinity of polymers should be considered (PLA is primarily amorphous, whereas PHB is highly crystalline), the $v(\mathrm{C}=\mathrm{O})$ band widths for PLA and PHB differed significantly. FTIR spectra showed a strong peak at $1755 \mathrm{~cm}^{-1}$, which is related to the amorphous carbonyl stretching vibration of PLA and remains constant in all the PLA_PHB blends. In addition, a sharp peak at $17 \overline{2} 3 \mathrm{~cm}^{-1}$ was observed in the spectra of PHB-containing systems. This peak is attributed to the stretching vibrations of crystalline carbonyl groups. The FTIR spectra of PLA_PHB blends showed the two major carbonyl stretching bands due to PLA and PHB, respectively, 

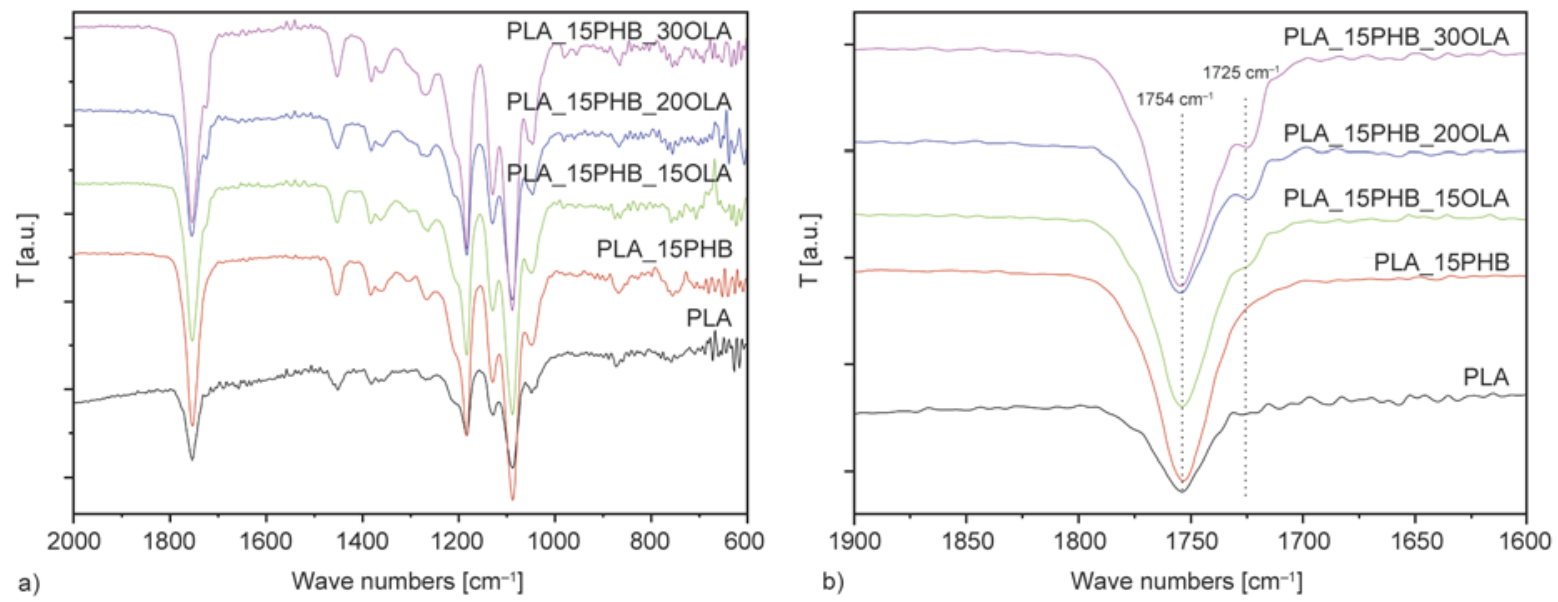

Figure 7. FT-IR spectra of PLA, PLA_PHB, and PLA_PHB_OLA films in ATR mode in the 2000-600 $\mathrm{cm}^{-1}$ frequency range (a) and $2000-1600 \mathrm{~cm}^{-1}$ (b).

and it was noticed that the intensity ratio of these two bands changed with the composition ratio [30]. As the OLA content was increased, the stretching vibrations of crystalline carbonyl groups increased gradually. However, no changes in the main carbonyl peak, which corresponds to PLA, were observed. This result indicates that PLA_PHB_OLA blends may be more easily crystallized as its proportion in the composite increased, forming phase-separated domains in the PLA matrix, and confirmed the DSC results.

\subsection{Mechanical properties}

The results of mechanical analysis for PLA, PLA_PHB and ternary PLA_PHB_OLA films are summarized in Table 3 and representative stressstrain curves are reported in Figure 8. As expected, the addition of the OLA plasticizer caused a substantial decrease in the materials toughness [21]. A progressive reduction in the elastic modulus was observed with the increase of the OLA content, when compared to neat PLA and PLA_PHB blends for 15,20 and $30 \mathrm{wt} \%$ OLA content, evidencing the decrease in rigidity for the plasticized compositions.

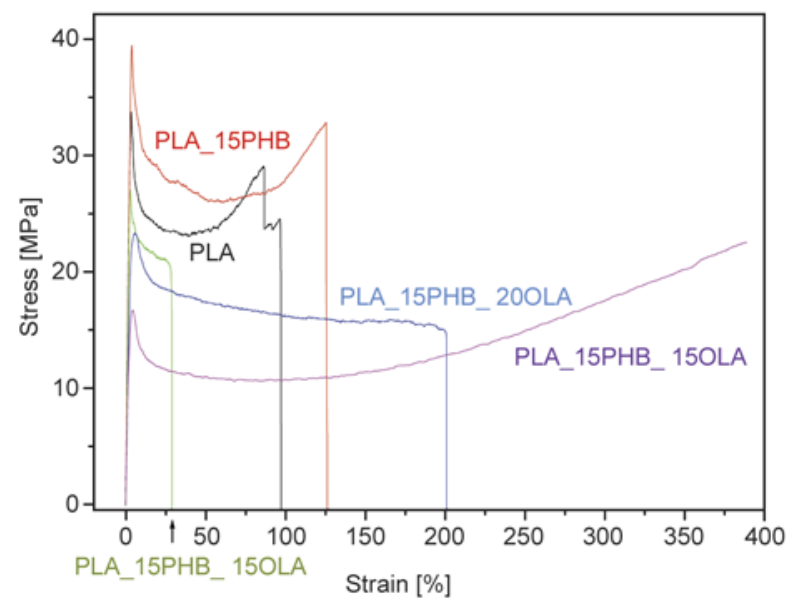

Figure 8. Representative stress-strain curve for the studied formulations

The higher modulus reduction was obtained at $30 \mathrm{wt} \%$ of OLA. In the meantime, the elongation at break of PLA_PHB films strongly increased with the addition of OLA (Table 3), showing an important enhancement in blends ductility that was well correlated with the decrease in $T_{\mathrm{g}}$ observed in DSC curves (Figure 5) and with the microstructure of the fracture surface analyzed by FESEM in Figure 3. The elongation at break increased to values as high as $400 \%$, indicating that the properties of PLA_PHB

Table 3. Results from tensile test for PLA, PLA_PHB and PLA_PHB_OLA systems

\begin{tabular}{|l|c|c|c|c|c|}
\hline \multirow{2}{*}{ Samples } & \multicolumn{5}{|c|}{ Mechanical properties } \\
\cline { 2 - 6 } & $\begin{array}{c}\boldsymbol{\sigma}_{\mathbf{Y}} \\
{[\mathbf{M P a}]}\end{array}$ & $\begin{array}{c}\boldsymbol{\varepsilon}_{\mathbf{Y}} \\
{[\mathbf{\%}]}\end{array}$ & $\begin{array}{c}\mathbf{\sigma}_{\mathbf{b}} \\
{[\mathbf{M P a}]}\end{array}$ & $\begin{array}{c}\boldsymbol{\varepsilon}_{\mathbf{b}} \\
{[\mathbf{\%}]}\end{array}$ & $\begin{array}{c}\mathbf{E}_{\mathbf{Y}} \\
{[\mathbf{M P a n g}]}\end{array}$ \\
\hline PLA & $40 \pm 7^{\mathrm{a}}$ & $3.4 \pm 0.4$ & $35 \pm 6^{\mathrm{a}}$ & $100 \pm 30^{\mathrm{a}}$ & $1300 \pm 180^{\mathrm{a}}$ \\
\hline PLA_15PHB & $40 \pm 5^{\mathrm{a}}$ & $3.8 \pm 0.5$ & $31 \pm 5^{\mathrm{a}}$ & $140 \pm 60^{\mathrm{a}, \mathrm{c}}$ & $1220 \pm 140^{\mathrm{a}}$ \\
\hline PLA_15PHB_15OLA & $31 \pm 3^{\mathrm{b}}$ & $3.1 \pm 0.3$ & $23 \pm 2^{\mathrm{b}}$ & $35 \pm 14^{\mathrm{b}}$ & $1120 \pm 60^{\mathrm{a}, \mathrm{c}}$ \\
\hline PLA_15PHB_20OLA & $23 \pm 4^{\mathrm{c}}$ & $3.3 \pm 0.9$ & $18 \pm 3^{\mathrm{b}}$ & $220 \pm 100^{\mathrm{c}}$ & $950 \pm 130^{\mathrm{d}}$ \\
\hline PLA_15PHB_30OLA & $16 \pm 3^{\mathrm{d}}$ & $3.9 \pm 0.4$ & $19 \pm 3^{\mathrm{b}}$ & $370 \pm 20^{\mathrm{d}}$ & $590 \pm 50^{\mathrm{e}}$ \\
\hline
\end{tabular}

${ }^{a-e}$ Different superscripts within the same column indicate significant differences between formulations $(p<0.05)$ 
films can be easily tuned from rigid to ductile. Films with $30 \mathrm{wt} \%$ OLA showed the highest elongation at break and homogeneity, since we measured low values of standard deviations. This behaviour could be explained by the reduction of the macromolecular chains cohesion when the plasticizer penetrates through the polymer matrix $[16,20]$.

\subsection{Barrier properties}

It was observed that the addition of $15 \mathrm{wt} \%$ PHB to the PLA matrix induced a significant reduction $(p<$ $0.05)$ in OTR e value of PLA film of ca. $35 \%$. This positive effect in the oxygen barrier properties could be caused by the increase in the PLA crystallinity by the addition of a highly crystalline biopolymer, such as PHB, previously discussed in the DSC analysis and already reported by Arrieta et al. [5].

The introduction of $20 \mathrm{wt} \%$ of OLA to the PLA_PHB blend induced a significant $(p<0.05)$ increase in the OTR e values up to ca. $70 \%$. This result could be caused by the increase in the free volume of the PLA_PHB matrix by the addition of the plasticizer and it could explain the reduction in the resistance of this plasticized film to oxygen transmission, as reported by other authors for the same polymer blends [5, 24, 20, 31]. However, the increase in the OLA content up to $30 \mathrm{wt} \%$ showed no significant differences $(p<0.05)$ in OTR $e$ values comparing with PLA_PHB blends. This result could be explained by the development of higher PLA crystallinity in the PLA_15PHB_30OLA blend, as stated by the X-ray diffraction and DSC analysis. This increase in crystallinity and difference revealed in the crystallization phenomena could induce higher tortuosity for the oxygen molecules path through the polymer film, counteracting the decrease in the resistance of this film to oxygen transmission caused by the introduction of the plasticizer.

It is interesting to compare these $O T R \cdot e$ results for PLA_PHB blends with those obtained for other polymers currently used in food packaging applications, such as low density polyethylene (LDPE) and polyethylene terephthalate (PET). All PLA_PHB formulations showed lower OTR'e values than those obtained for LDPE (around $160 \mathrm{~cm}^{3} \cdot \mathrm{mm} \cdot \mathrm{m}^{-2} \cdot \mathrm{day}^{-1}$ ), but they were higher than those for PET (around $3 \mathrm{~cm}^{3} \cdot \mathrm{mm} \cdot \mathrm{m}^{-2} \cdot \mathrm{day}^{-1}$ ), indicating that the PLA_PHB blends could be acceptable for such applications with medium oxygen barrier. In addition, it should be highlighted that plasticized formulations showed
Table 4. Oxygen Transmission Rate per film thickness $(O T R \cdot e)$ and Water Vapor Permeability $(W V P)$ coefficients for PLA, PLA_PHB and PLA_PHB_OLA systems

\begin{tabular}{|c|c|c|}
\hline \multirow[b]{2}{*}{ Samples } & \multicolumn{2}{|c|}{ Barrier properties } \\
\hline & $\begin{array}{c}\text { OTR } \cdot e \\
{\left[\mathrm{~cm}^{3} \cdot \mathrm{mm} \cdot \mathrm{m}^{-2} \cdot \mathrm{day}^{-1}\right]}\end{array}$ & $\begin{array}{c}W V P \cdot 10^{14} \\
{\left[\mathrm{~kg} \cdot \mathrm{m} \cdot \mathrm{Pa}^{-1} \cdot \mathrm{s}^{-1} \cdot \mathrm{m}^{-2}\right]}\end{array}$ \\
\hline PLA & $22.9 \pm 0.4^{\mathrm{a}}$ & $1.88 \pm 0.21^{\mathrm{a}}$ \\
\hline PLA_15PHB & $14.9 \pm 0.8^{b}$ & $1.54 \pm 0.21^{\mathrm{a}, \mathrm{c}}$ \\
\hline PLA_15PHB_20OLA & $25.5 \pm 2.1^{\mathrm{a}}$ & $1.19 \pm 0.04^{\mathrm{b}, \mathrm{c}}$ \\
\hline PLA_15PHB_30OLA & $18.6 \pm 1.4^{b}$ & $0.97 \pm 0.13^{\mathrm{b}}$ \\
\hline
\end{tabular}

${ }^{\mathrm{a}-\mathrm{c}}$ Different superscripts within the same column indicate significant differences between formulations $(p<0.05)$

OTR e results lower than those obtained in a previous work for PLA plasticized with OLA at 15, 20 and $25 \mathrm{wt} \%$ under the same experimental conditions [20].

Water vapour permeability coefficients determined for the same blends are also summarized in Table 4. No significant reduction $(p<0.05)$ in WVP of PLA was observed after the addition of $15 \mathrm{wt} \%$ PHB as well as in WVP data for PLA_PHB blends with $20 \mathrm{wt} \%$ OLA. However, a positive effect in the water vapour barrier properties was detected for the PLA_PHB films plasticized with $30 \mathrm{wt} \%$ OLA, with a reduction ca. $37 \%(p<0.05)$ in the $W V P$ value of the unplasticized PLA_PHB film. Several counteracting factors, in different degree, could affect the water vapour permeability of these samples. As already discussed from the OTR $e$ results, the addition of OLA in high concentrations increases the free volume available in the PLA_PHB structure, reducing the resistance of films to water vapour transmission. But, in contrast, the development of crystallinity and the increase in the material hydrophobic character caused by OLA results in some decreases in WVP coefficients, inducing a positive effect in the barrier properties to water vapour.

In summary, it can be concluded that the addition of $30 \mathrm{wt} \%$ OLA enhanced significantly $(p<0.05)$ the oxygen and water vapour barrier properties of neat PLA and PLA_PHB composites by the development of crystalline structures in these blends.

\subsection{Migration properties}

One of the necessary conditions for a polymeric material to be used in food packaging applications is their overall migration limit, which should be lower than those limits established in the current legislation (European Commission Regulation, 2011) [27], ensuring that the total amount of non-volatile 


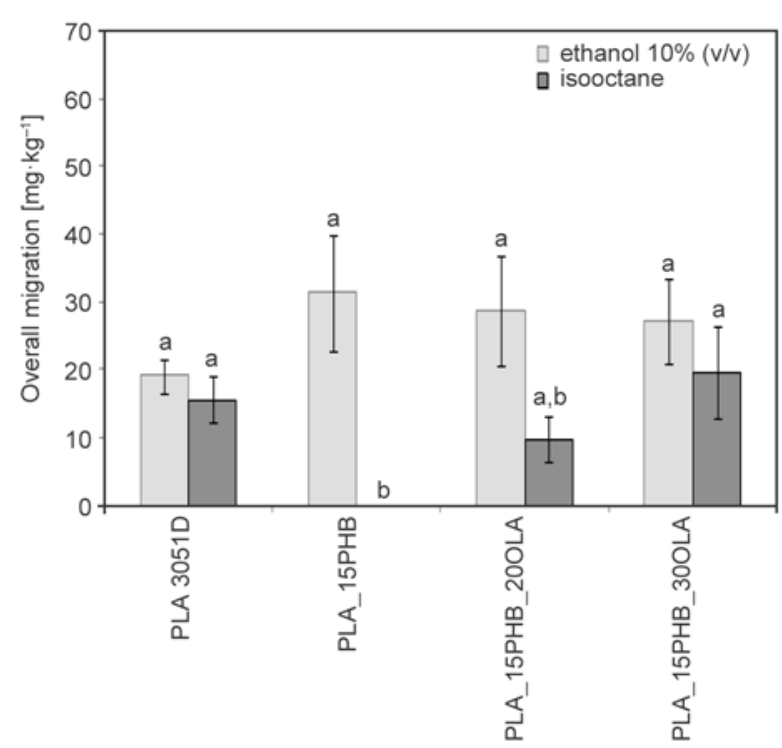

Figure 9. Overall migration values in ethanol $10 \%(\mathrm{v} / \mathrm{v})$ and isooctane for PLA and PLA_PHB based systems. Different superscripts on the bars indicate significant differences between samples $(p<$ $0.05)$.

substances that might transfer into foodstuff from polymers does not represent a risk to the consumer. The overall migration values of PLA and PLA_PHB composites in ethanol $10 \%(\mathrm{v} / \mathrm{v})$ and isooctane were compared in Figure 9. It was observed that in all cases, the overall migration values in both food simulants were lower than the legislative limit $60 \mathrm{mg} \cdot \mathrm{kg}^{-1}$.

In the case of ethanol $10 \%(\mathrm{v} / \mathrm{v})$, no significant differences $(p<0.05)$ were observed between the overall migration values for all samples. However, considering results obtained in the isooctane simulant, it was noted that the addition of PHB to the PLA matrix reduced significantly (not detected data, $p<$ $0.05)$ the overall migration to values lower than the limit of detection of the used method, while plasticized samples showed similar values $(p<0.05)$ than neat PLA.

In general terms, overall migration in ethanol $10 \%(\mathrm{v} / \mathrm{v})$ was higher than in isooctane for PLA_PHB and PLA_PHB_20OLA, while similar migration values in both simulants were detected for neat PLA and PLA_PHB_30OLA films. These results could be explained by the different polarity and solubility between both biopolymers, the potential migrant compounds and the food simulants. Since PLA, PHB and OLA are non-polar compounds and consequently they are insoluble in water, some other chemicals potentially present in these formulations, such as residual lactic acid and oligomers of lactic acid with low molar mass (due to the chain scission of PLA and OLA caused by processing) are polar compounds and they are water-soluble. These compounds could contribute to the total mass transfer in ethanol $10 \%(\mathrm{v} / \mathrm{v})$, as reported by other authors [3234]. It should be noted that after the migration test in ethanol $10 \%(\mathrm{v} / \mathrm{v})$ all materials lost their transparency turning into opaque films. This change in their visual aspect could be due to the water absorption that produced hydrolytic degradation and chain scission, increasing the amount of low molar mass compounds able to migrate in this simulant. However, no visual changes in the surface of films immersed in isooctane were observed, and transparency was preserved after the migration test.

Another important factor is the testing temperature and total time applied to the migration test in ethanol $10 \%(\mathrm{v} / \mathrm{v})\left(40^{\circ} \mathrm{C}\right.$ for 10 days $)$ and isooctane ( $20^{\circ} \mathrm{C}, 2$ days). The first temperature is close to $T_{\mathrm{g}} \mathrm{val}-$ ues of these samples, as observed in DSC tests and, as a consequence, samples in ethanol 10\% (v/v) could suffer some structural changes and the development of crystallinity that could facilitate the plasticizer exudation. In the case of migration in the non-polar simulant (isooctane), some increase in the migration values $(p<0.05)$ was detected at high OLA concentrations in the PLA_PHB blend. The non-polar nature of this plasticizer and its relative low average molar mass could explain this result, allowing their release in the food simulant.

\section{Conclusions}

Binary and ternary films made of PLA, PHB and OLA were successfully prepared under optimized extrusion conditions, followed by a filmature procedure. Mechanical, thermal, morphological and functional properties were investigated as a function of the OLA composition ratio and the adequate formulation was selected to get the desired performance in eco-friendly films.

The high efficiency of OLA as plasticizer was observed for PLA_PHB blends, as it caused a significant decrease on their glass transition temperature, which was well correlated with a considerable improvement of their ductile properties. A single $T_{\mathrm{g}}$ value was observed in all the studied formulations and no apparent phase separation was detected, confirming the high compatibility between OLA with the PLA_PHB matrix. 
Mechanical properties underlined that the elongation at break increased as high as $400 \%$, indicating that PLA_PHB films can be easily turned from rigid to ductile. Water vapor permeability $(W V P)$ tests showed a modulation in all the system with OLA respect to neat PLA and PLA_PHB blends: WVP decrease in the PLA_15PHB_30OLA of 37\% respect to PLA_PHB blend and of $48 \%$ respect to neat PLA films, while oxygen transmission rate $(O T R)$ showed increased values respect to PLA_PHB film, but improved respect to the neat PLA films.

The improvement in the barrier properties are related with the higher crystallinity of the plasticized PLA_PHB blends ensuring a good protection to foodstuff by decreasing significantly the oxygen transmission rate and water vapor permeability values of neat PLA films.

Migration tests were performed by following the current legislation for food contact materials in both non-polar and polar simulants and no problems were observed since the obtained overall migration values were well below the legislative limit. According to the analyzed properties, the PLA_PHB blend with $30 \mathrm{wt} \%$ OLA was selected as the optimum formulation, since it offered the best compromise between ductile and oxygen and water vapor barrier properties, with no migration problems for perspective application as food packaging material.

\section{Acknowledgements}

This research was financed by the SAMSUNG GRO PROGRAMME 2012.

\section{References}

[1] Arrieta M. P., Fortunati E., Dominici F., Rayón E., López J., Kenny J. M.: PLA-PHB/cellulose based films: Mechanical, barrier and disintegration properties. Polymer Degradation and Stability, 107, 139-149 (2014). DOI: $10.1016 /$ j.polymdegradstab.2014.05.010

[2] Lim J. S., Park K-I., Chung G. S., Kim J. H.: Effect of composition ratio on the thermal and physical properties of semicrystalline PLA/PHB-HHx composites. Materials Science and Engineering: C, 33, 2131-2137 (2013).

DOI: $10.1016 / \mathrm{j} . \mathrm{msec} .2013 .01 .030$

[3] Boufarguine M., Guinault A., Miquelard-Garnier G., Sollogoub C.: PLA/PHBV films with improved mechanical and gas barrier properties. Macromolecular Materials and Engineering, 298, 1065-1073 (2013).

DOI: $10.1002 /$ mame.201200285
[4] Arrieta M. P., Fortunati E., Dominici F., Rayón E., López J., Kenny J. M.: Multifunctional PLA-PHB/cellulose nanocrystal films: Processing, structural and thermal properties. Carbohydrate Polymers, 107, 1624 (2014).

DOI: $10.1016 /$ j.carbpol.2014.02.044

[5] Arrieta M. P., Samper M. D., López J., Jiménez A.: Combined effect of poly(hydroxybutyrate) and plasticizers on polylactic acid properties for film intended for food packaging. Journal of Polymers and the Environment, 22, 460-470 (2014).

DOI: $10.1007 / \mathrm{s} 10924-014-0654-\mathrm{y}$

[6] Arrnentano I., Bitinis N., Fortunati E., Mattioli S., Rescignano N., Verdejo R., López-Manchado M. A., Kenny J. M.: Multifunctional nanostructured PLA materials for packaging and tissue engineering. Progress in Polymer Science, 38, 1720-1747 (2013).

DOI: 10.1016/j.progpolymsci.2013.05.010

[7] Madhavan Nampoothiri K., Nair N. R., John R. P.: An overview of the recent developments in polylactide (PLA) research. Bioresource Technology, 101, 84938501 (2010).

DOI: $10.1016 /$ j.biortech.2010.05.092

[8] Rasal R. M., Janorkar A. V., Hirt D. E.: Poly(lactic acid) modifications. Progress in Polymer Science, 35, 338-356 (2010).

DOI: $10.1016 / \mathrm{j}$. progpolymsci.2009.12.003

[9] Fan Y., Nishida H., Shirai Y., Tokiwa Y., Endo T.: Thermal degradation behaviour of poly(lactic acid) stereocomplex. Polymer Degradation and Stability, 86, 197-208 (2004).

DOI: $10.1016 /$ j.polymdegradstab.2004.03.001

[10] Noda I., Satkowski M. M., Dowrey A. E., Marcott C.: Polymer alloys of nodax copolymers and poly(lactic acid). Macromolecular Bioscience, 4, 269-275 (2004). DOI: 10.1002/mabi.200300093

[11] Zhang L., Xiong C., Deng X.: Miscibility, crystallization and morphology of poly( $\beta$-hydroxybutyrate)/poly (D,L-lactide) blends. Polymer, 37, 235-241 (1996). DOI: 10.1016/0032-3861(96)81093-7

[12] Zhang M., Thomas N. L: Blending polylactic acid with polyhydroxybutyrate: The effect on thermal, mechanical, and biodegradation properties. Advances in Polymer Technology, 30, 67-79 (2011). DOI: $10.1002 / \mathrm{adv} .20235$

[13] Bucci D. Z., Tavares L. B. B., Sell I.: PHB packaging for the storage of food products. Polymer Testing, 24, 564-571 (2005).

DOI: $10.1016 /$ j.polymertesting.2005.02.008

[14] Arrieta M. P., del Mar Castro-López M., Rayón E., Barral-Losada L. F., López-Vilariño J. M., López J., González-Rodríguez M. V.: Plasticized poly(lactic acid)-poly(hydroxybutyrate) (PLA-PHB) blends incorporated with catechin intended for active food-packaging applications. Journal of Agricultural and Food Chemistry, 62, 10170-10180 (2014).

DOI: $10.1021 / \mathrm{jf5} 029812$ 
[15] Imre B., Pukánszky B.: Compatibilization in bio-based and biodegradable polymer blends. European Polymer Journal, 49, 1215-1233 (2013).

DOI: $10.1016 /$ j.eurpolymj.2013.01.019

[16] Abdelwahab M. A., Flynn A., Chiou B-S., Imam S., Orts W., Chiellini E.: Thermal, mechanical and morphological characterization of plasticized PLA-PHB blends. Polymer Degradation and Stability, 97, 18221828 (2012).

DOI: 10.1016/j.polymdegradstab.2012.05.036

[17] Ljungberg N., Wesslén B.: Preparation and properties of plasticized poly(lactic acid) films. Biomacromolecules 6, 1789-1796 (2005).

DOI: $10.1021 / \mathrm{bm} 050098 \mathrm{f}$

[18] Kulinski Z., Piorkowska E.: Crystallization, structure and properties of plasticized poly(L-lactide). Polymer, 46, 10290-10300 (2005).

DOI: 10.1016/j.polymer.2005.07.101

[19] Martin O., Avérous L.: Poly(lactic acid): Plasticization and properties of biodegradable multiphase systems. Polymer, 42, 6209-6219 (2001). DOI: 10.1016/S0032-3861(01)00086-6

[20] Burgos N., Martino V. P., Jiménez A.: Characterization and ageing study of poly(lactic acid) films plasticized with oligomeric lactic acid. Polymer Degradation and Stability, 98, 651-658 (2013).

DOI: $10.1016 /$ j.polymdegradstab.2012.11.009

[21] Burgos N., Tolaguera D., Fiori S., Jiménez A.: Synthesis and characterization of lactic acid oligomers: Evaluation of performance as poly(lactic acid) plasticizers. Journal of Polymers and the Environment, 22, 227235 (2014). DOI: $10.1007 / \mathrm{s} 10924-013-0628-5$

[22] Xiao H., Liu F., Jiang T., Yeh J-T.: Kinetics and crystal structure of isothermal crystallization of poly(lactic acid) plasticized with triphenyl phosphate. Journal of Applied Polymer Science, 117, 2980-2992 (2010).

DOI: 10.1002/app.32225

[23] Fiori S., Ara P.: Method for plasticizing lactic acid polymers. World Patent WO2009092825 (2009).

[24] ASTM E96/E96M-05: Standard test methods for water vapor transmission of materials (2005).

[25] Union Guidelines on Regulation (EU) $N^{\circ} 10 / 2011$ on plastic materials and articles intended to come into contact with food. Official Journal of European Communities (2011).
[26] Commission directive 2002/72/EC relating to plastic materials and articles intended to come into contact with foodstuffs. Official Journal of European Communities (2002).

[27] Martino V. P., Jiménez A., Ruseckaite R. A.: Processing and characterization of poly(lactic acid) films plasticized with commercial adipates. Journal of Applied Polymer Science, 112, 2010-2018 (2009).

DOI: 10.1002/app.29784

[28] Martino V. P., Ruseckaite R. A., Jiménez A.: Ageing of poly(lactic acid) films plasticized with commercial polyadipates. Polymer International, 58, 437-444 (2009).

DOI: $10.1002 /$ pi.2556

[29] Fortunati E., Armentano I., Zhou Q., Iannoni A., Saino E., Visai L., Berglund L. A., Kenny J. M.: Multifunctional bionanocomposite films of poly(lactic acid), cellulose nanocrystals and silver nanoparticles. Carbohydrate Polymers, 87, 1596-1605 (2012).

DOI: $10.1016 /$ j.carbpol.2011.09.066

[30] Vogel C., Wessel E., Siesler H. W.: FT-IR imaging spectroscopy of phase separation in blends of poly(3hydroxybutyrate) with poly(L-lactic acid) and poly( $\varepsilon$ caprolactone). Biomacromolecules, 9, 523-527 (2007). DOI: $10.1021 / \mathrm{bm} 701035 \mathrm{p}$

[31] Laohakunjit N., Noomhorm A.: Effect of plasticizers on mechanical and barrier properties of rice starch film. Starch-Stärke, 56, 348-356 (2004). DOI: $10.1002 /$ star.200300249

[32] Martino V. P., Ruseckaite R. A., Jiménez A., Averous L.: Correlation between composition, structure and properties of poly(lactic acid)/polyadipate-based nanobiocomposites. Macromolecular Materials and Engineering, 295, 551-558 (2010). DOI: $10.1002 /$ mame.200900351

[33] Vu D. T., Kolah A. K., Asthana N. S., Peereboom L., Lira C. T., Miller D. J.: Oligomer distribution in concentrated lactic acid solutions. Fluid Phase Equilibria, 236, 125-135 (2005).

DOI: 10.1016/j.fluid.2005.06.021

[34] Höglund A., Hakkarainen M., Albertsson A-C.: Migration and hydrolysis of hydrophobic polylactide plasticizer. Biomacromolecules, 11, 277-283 (2009).

DOI: $10.1021 / \mathrm{bm} 901157 \mathrm{~h}$ 